\title{
Intraductal Papilloma Without Atypia on Image- Guided Breast Biopsy: Upgrade Rates to Carcinoma at Surgical Excision
}

\author{
Doris Leithner $^{\mathrm{a}}$ Benjamin Kaltenbach ${ }^{\mathrm{a}}$ Petra Hödl $^{\mathrm{b}}$ Volker Möbus ${ }^{\mathrm{c}}$ Volker Brandenbusch ${ }^{\mathrm{d}}$ \\ Stephan Falk ${ }^{\mathrm{e}}$ Clara Park $^{\mathrm{a}}$ Thomas J. Vogl ${ }^{\mathrm{a}}$ Markus Müller-Schimpfle ${ }^{f}$ \\ a Department of Diagnostic and Interventional Radiology, University Hospital Frankfurt, Frankfurt/M., Germany; \\ ${ }^{b}$ Institute of Pathology, Klinikum Frankfurt Höchst, Frankfurt/M., Germany; \\ ${ }^{c}$ Department of Obstetrics and Gynecology, Klinikum Frankfurt Höchst, Frankfurt/M., Germany; \\ ${ }^{\mathrm{d}}$ Mammography Screening, Diagnostic Breast Center Turmcarée, Frankfurt/M., Germany; \\ e OptiPath, Pathology Associates, Frankfurt/M., Germany; \\ ${ }^{f}$ Institute of Radiology (RZI), Klinikum Frankfurt Höchst, Academic Teaching Hospital of the University of Frankfurt, Frankfurt/M., Germany
}

\section{Keywords}

Breast cancer · Imaging · Biopsy · Papilloma

\section{Summary}

Background: The management of intraductal papilloma without atypia (IDP) in breast needle biopsy remains controversial. This study investigates the upgrade rate of IDP to carcinoma and clinical and radiologic features predictive of an upgrade. Methods: Patients with a diagnosis of IDP on image-guided (mammography, ultrasound, magnetic resonance imaging) core needle or vacuum-assisted biopsy and surgical excision of this lesion at a certified breast center between 2007 and 2017 were included in this institutional review board-approved retrospective study. Appropriate statistical tests were performed to assess clinical and radiologic characteristics associated with an upgrade to malignancy at excision. Results: For 60 women with 62 surgically removed IDPs, the upgrade rate to malignancy was $16.1 \%$ (10 upgrades, 4 invasive ductal carcinoma, 6 ductal carcinoma in situ). IDPs with upgrade to carcinoma showed a significantly greater distance to the nipple $(63.5$ vs. $36.8 \mathrm{~mm} ; \mathrm{p}=$ 0.012 ). No significant associations were found between upgrade to carcinoma and age, menopausal status, lesion size, microcalcifications, BI-RADS descriptors, initial BI-RADS category, and biopsy modality. Conclusion: The upgrade rate at excision for IDPs diagnosed with needle

D. Leithner and B. Kaltenbach contributed equally and share first authorship. biopsy was higher than expected according to some guideline recommendations. Observation only might not be appropriate for all patients with IDP, particularly for those with peripheral IDP.

(c) 2018 S. Karger GmbH, Freiburg

\section{Introduction}

Papillary lesions of the breast include a wide range of benign, atypical, and malignant tumors, which cannot be reliably distinguished using imaging alone [1]. Surgical excision is generally recommended for atypical papilloma diagnosed with image-guided breast biopsy, due to its high upgrade rates to breast cancer [2-5]. However, the management of intraductal papilloma without atypia (IDP) on image-guided breast biopsy remains controversial due to divergent results in previous studies reporting upgrade rates to malignancy after excision ranging from 0 to $25 \%$ [6-11]. It has been suggested that image-guided biopsy is limited by tissue fragmentation and small specimen size and therefore might miss areas with atypia and breast cancer. Therefore excision of IDP found on image-guided biopsy is frequently recommended in interdisciplinary post-biopsy conferences. In contrast, other studies found low upgrade rates at surgical excision and concluded that imaging surveillance might be sufficient $[6,12,13]$.

Previous studies investigated which clinical and imaging features are predictive for an upgrade to carcinoma and suggested

\section{KARGER}

Fax +497614520714
๑๑ 2018 S. Karger GmbH, Freiburg 
characteristics such as larger lesion size [7], presence of microcalcifications [14], older patient age [5], and palpable mass lesions [11]. However, to our knowledge, almost all of these previous studies focused on only a single imaging modality, and there is still no consensus as to which imaging features warrant surgical excision.

Hence, this study aimed to investigate the upgrade rate to breast cancer at excision of IDP diagnosed on ultrasound(US)-, mammography(MG)-, and magnetic resonance imaging(MRI)guided breast biopsy, and to identify clinical and imaging descriptors predictive of malignancy.

\section{Patients and Methods}

\section{Study Population}

The institutional review board approved this retrospective study with a waiver for written consent. A computerized search of the breast center database (ODS easy, Asthenis, Aschheim, Germany) identified 71 patients with a needle biopsy diagnosis of IDP and subsequent surgical excision of this lesion between $03 / 2007$ and 03/2017. Thus, a total of 60 patients with 62 IDPs were included in the study.

Radiologic information was assessed in consensus by 2 radiologists with more than 10 years' experience in breast radiology, using the imaging modality with which the biopsy was conducted. Lesion laterality and size, nipple discharge, presence of calcifications, distance between nipple and lesion, and BIRADS (Breast Imaging Reporting and Data System) category according to the revised American College of Radiology BI-RADS lexicon were evaluated. In patients with multiple IDP, all lesions were rated. Clinical information, such as age at diagnosis and menopausal status, were retrieved from the database. Char acteristics of the carcinoma such as tumor type and grade were recorded. A malignant upgrade was defined as the presence of breast cancer and/or ductal carcinoma in situ (DCIS) in the surgically removed lesion.

\section{Biopsy Procedure}

Core needle biopsy (CNB) was used for mass lesions using a 14-gauge coaxial biopsy system (HistoCore, BIP, Tuerkenfeld, Germany). Vacuum-assisted biopsy (VAB) was performed for non-mass lesions using a 10-gauge coaxial needle system (Vacora, Bard Biopsy Systems, Tempe, AZ, USA) or a 9-gauge automated VAB system (ATEC, Hologic, Marlborough, MA, USA). 12 biopsy cylinders were sampled for each suspicious lesion. In the case of microcalcifications within the lesion, biopsy success was evaluated with a post-procedural radiograph of the specimen.

For both CNB and VAB, the imaging modality for needle guidance was chosen based on the best lesion visualization. US guidance (Logiq E9, GE Healthcare, Milwaukee, WI, USA), MG stereotactic guidance (FCR PROFECT CS Plus, Fujifilm, Minato, Japan; DMR Plus, GE Healthcare) with a panning angle of $\pm 15^{\circ}$, or MRI guidance (Symphony 1.5 Tesla, Siemens Healthcare, Erlangen, Germany) were used. Biopsies were performed by 2 board-certified breast radiologists with $>10$ and $>20$ years' experience, respectively.

\section{Histopathologic Analysis}

All patients included in the present study underwent subsequent surgical excision after initial biopsy for the following reasons: potential non-representative needle biopsy, pain, patient's wish, initial BI-RADS 5 classification with discordant findings after biopsy, size progress, nipple discharge.

Both the initial biopsy and the postoperative specimen were analyzed by a pathologist with $>15$ years' experience using standardized histologic techniques and additional immunohistochemical methods if necessary.

Statistical Analysis

Statistical tests were performed using IBM SPSS Statistics (version 22.0 IBM, Armonk, NY, USA). A Mann-Whitney test was used to assess the associa- tion of continuous values with an upgrade, while categorical data was assessed using the chi-square test and the Fisher's exact test. A p value of $<0.05$ was considered as statistically significant. Continuous data is given as mean \pm standard deviation. For patients with 2 IDPs, analyses of radiologic features were performed for both lesions, whereas clinical characteristics were evaluated per patient.

\section{Results}

\section{Patient Characteristics}

The study population consisted of 60 women with 62 lesions with a CNB diagnosis of IDP (58 patients had 1 IDP, 2 had 2 IDPs). Mean patient age at diagnosis was 54.7 years (range 32-79 years). $20(33.3 \%)$ patients were premenopausal, 4 (6.7\%) were perimenopausal, and $36(60 \%)$ were postmenopausal. Galactography was performed in 5 patients due to secretion. All lesions were surgically removed after an interval of up to 3 months (mean 2.1 months). The upgrade rate to carcinoma was $16.1 \%$ (10/62 lesions). Of those patients, 3 were premenopausal, while 7 were postmenopausal. Invasive ductal carcinoma was found in 4 lesions (2 grade 1, 2 grade 2 ), while the other 6 lesions showed DCIS after excision (1 grade 1 , 4 grade 2,1 grade 3 ).

Age and menopausal status were not associated with a malignant upgrade $(\mathrm{p}=0.174, \mathrm{p}=1.0$, respectively). When peri- and postmenopausal patients were considered together, again no association was found $(\mathrm{p}=0.871)$ with age

\section{Radiologic Characteristics}

The mean size of the target lesion was $11.5 \mathrm{~mm}$ (range 2-31 $\mathrm{mm})$. The mean and median distance to the nipple were 41.5 and $40 \mathrm{~mm}$ (range 5-130 $\mathrm{mm}$ ), respectively. 39 (62.9\%) lesions had a distance of $>2 \mathrm{~cm}$ to the nipple. All measurements were performed in the modality with which the biopsy was conducted. The lesions were 46 masses, 12 non-mass lesions, and 2 architectural distortions. Microcalcifications were present in 8 cases. 4 lesions were initially classified as BI-RADS 3, 54 lesions as BI-RADS 4, and 4 lesions as BI-RADS 5. 9 patients had a history of breast cancer in the contralateral breast.

Fig. 1. Ultrasoundguided core needle biopsy of a BI-RADS 5 lesion (a transverse image; b longitudinal image) in a 65-year-old woman showing benign papilloma without atypia, which was considered a radiologicpathologic discordance. Upgraded diagnosis after surgical excision was ductal carcinoma in situ.

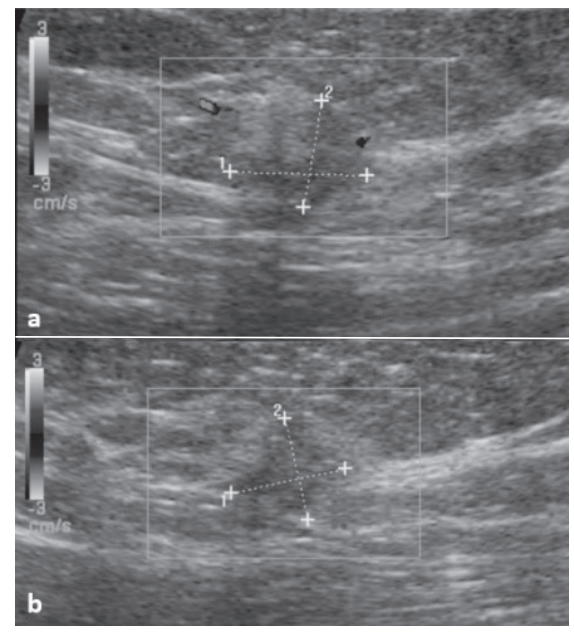


Table 1. Assessment of intraductal papillomas without atypia according to the upgrade status at excision. Distance to the nipple in $\mathrm{mm}$ was significantly greater in lesions with an upgrade at excision, while the other characteristics did not reach significance

\begin{tabular}{|c|c|c|c|c|}
\hline & $\begin{array}{l}\text { Overall } \\
(\mathrm{n}=62)\end{array}$ & $\begin{array}{l}\text { No upgrade } \\
(\mathrm{n}=52)\end{array}$ & $\begin{array}{l}\text { Upgrade } \\
(\mathrm{n}=10)\end{array}$ & $\mathrm{p}$ value \\
\hline Age, mean $\pm \mathrm{SD}$, years & $54.7 \pm 12.6$ & $53.8 \pm 12.6$ & $59.7 \pm 11.7$ & 0.174 \\
\hline Menopausal status, $\mathrm{n}$ & & & & 0.871 \\
\hline Premenopausal & 20 & 18 & 3 & \\
\hline Peri-/postmenopausal & 42 & 34 & 7 & \\
\hline \multicolumn{5}{|l|}{ Tumor size } \\
\hline Mean \pm SD, mm & $11.5 \pm 7.1$ & $11.3 \pm 7.0$ & $12.3 \pm 8.3$ & 0.941 \\
\hline$\geq 15 \mathrm{~mm}, \mathrm{n}$ & 15 & 9 & 2 & 1.000 \\
\hline$<15 \mathrm{~mm}, \mathrm{n}$ & 47 & 43 & 8 & \\
\hline Distance to nipple ${ }^{\mathrm{a}}$, mean $\pm \mathrm{SD}, \mathrm{mm}$ & $41.5 \pm 27.6$ & $36.8 \pm 24.2$ & $63.5 \pm 32.8$ & 0.012 \\
\hline Tumor characteristics, $\mathrm{n}$ & & & & 0.808 \\
\hline Mass & 46 & 40 & 6 & \\
\hline Non-mass & 12 & 10 & 2 & \\
\hline Architectural distortion & 2 & 2 & 0 & \\
\hline Microcalcifications, $\mathrm{n}$ & & & & 1.000 \\
\hline Yes & 8 & 7 & 1 & \\
\hline No & 54 & 35 & 9 & \\
\hline Initial BI-RADS category, $\mathrm{n}$ & & & & 0.805 \\
\hline BI-RADS 3 & 4 & 4 & 0 & \\
\hline BI-RADS 4 & 54 & 46 & 8 & \\
\hline BI-RADS 5 & 4 & 2 & 2 & \\
\hline $\begin{array}{l}\text { History of breast cancer in the } \\
\text { contralateral breast, } \mathrm{n}\end{array}$ & & & & 0.629 \\
\hline Yes & 9 & 7 & 2 & \\
\hline No & 53 & 45 & 8 & \\
\hline Biopsy procedure, $n$ & & & & 1.000 \\
\hline CNB & 48 & 40 & 8 & \\
\hline $\mathrm{VAB}$ & 14 & 12 & 2 & \\
\hline Biopsy guidance, $n$ & & & & 0.901 \\
\hline US & 45 & 37 & 8 & \\
\hline MG & 12 & 10 & 2 & \\
\hline MRI & 5 & 5 & 0 & \\
\hline
\end{tabular}

${ }^{a}$ Distance to the nipple in mm was significantly greater in lesions with an upgrade at excision, while the other characteristics did not reach significance.

$\mathrm{SD}=$ Standard deviation; $\mathrm{CNB}$ = core needle biopsy; $\mathrm{VAB}$ = vacuum-assisted biopsy; US = ultrasound; $\mathrm{MG}=$ mammography; $\mathrm{MRI}=$ magnetic resonance imaging.
IDPs with upgrade to carcinoma after excision showed a significantly greater distance between nipple and lesion (63.5 vs. 36.8 $\mathrm{mm} ; \mathrm{p}=0.012$ ). No association was found between imaging characteristics such as lesion size $(\mathrm{p}=0.941)$, presence of microcalcifications ( $\mathrm{p}=1.0$ ), initial BI-RADS category $(\mathrm{p}=0.805)$, and malignancy after excision.

\section{Biopsy Procedure Characteristics}

US-guided biopsies were performed in 45 (71\%) cases, 12 (3.2\%) biopsies were MG-guided, and 5 (6.5\%) biopsies were MRIguided VAB. Overall, VAB was used for 14 (22.6\%) IDPs, and 48 (77.4\%) were sampled using CNB. Of the 10 malignant upgrades, 8 were biopsied with US-guided CNB, and 2 with MG-guided stereotactic VAB. No association between biopsy technique or guidance and malignant upgrade was found ( $\mathrm{p}=1.0 ; \mathrm{p}=0.901)$. All details are outlined in table 1 , and figures $1-3$ show examples of imaging and biopsy findings in patients.

\section{Discussion}

It is undisputed that surgical excision is required when an atypical papilloma is found in breast biopsy material, due to the high risk for synchronous or metachronous carcinoma [15]. At the same time, the management of IDPs, which are regarded as benign proliferative disease, remains controversial, and patient numbers in previous studies are limited. An international consensus conference on B3 lesions decided that benign papilloma should undergo 
Fig. 2. 53-year-old woman with a $1.3-\mathrm{cm}$ mass on $\mathbf{a}, \mathbf{b}$ mammography and c ultrasound, initially classified as BI-RADS 4. Mammographyguided core needle biopsy revealed benign papilloma without atypia. Diagnosis was confirmed after surgical excision.

Fig. 3. 62-year-old woman with a BI-RADS 5 lesion on a mammography and $\mathbf{b}$ ultrasound. Benign papilloma without atypia was diagnosed with ultrasound-guided biopsy, whereas biopsy of a suspicious lymph node in the left axilla (c) revealed a metastasis of an invasive carcinoma. Subsequent surgical excision of the breast lesion confirmed this diagnosis.
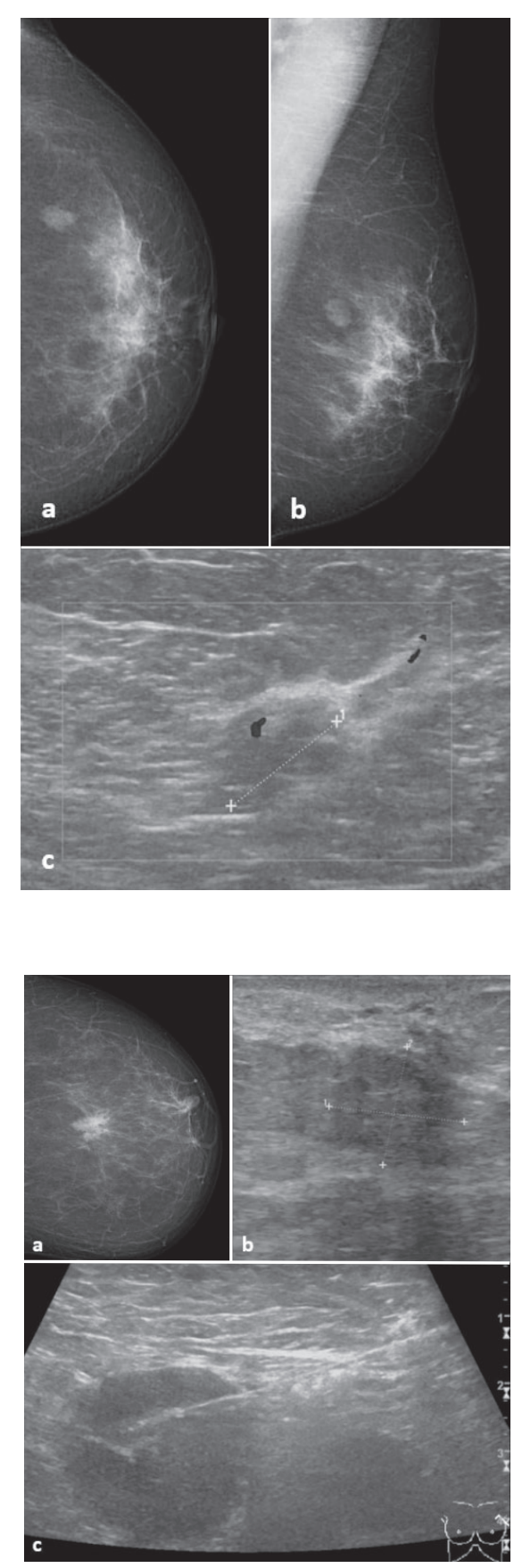

IDP based on only a single imaging modality with a focus on US [19], while our study evaluated both CNB and VAB guided by MG, US, and MRI.

The upgrade rate to carcinoma at excision of IDP diagnosed with biopsy has been investigated in multiple previous studies with conflicting results. In a recent study, Pareja et al. [6] found a malignant upgrade rate of $2.3 \%$ in 171 radiologic-pathologic concordant lesions. In a study cohort of 77 patients, no malignant upgrades were reported, and 100 patients were stable according to imaging over the course of 36 months [20]. Prospective studies reported an upgrade rate of $4 \%$ in 100 IDPs [7], and no upgrades in 49 cases [21]. Other studies have reported similar findings, with upgrade rates of $2.6 \%$ in 230 lesions [12]. However, multiple studies report substantially higher upgrade rates such as $6.3 \%$ in 154 patients [11] or $8.9 \%$ in 234 patients [22]. In another 80 patients, an even higher upgrade rate of $19 \%$ was found [23]. Our results suggest that the upgrade rate to DCIS or invasive carcinoma at excision of IDP is substantial, suggesting that observation only might not be an appropriate management of all patients with an IDP diagnosed with biopsy.

Papillomas are classified as central and peripheral, or single and multiple, with peripheral lesions showing a significantly higher risk for breast cancer than central papilloma in previous studies $[4,24$, $25]$. In our study, a greater distance to the nipple was significantly associated with a higher upgrade rate ( 63.5 vs. $36.8 \mathrm{~mm}$; $\mathrm{p}=0.012$ ). Due to the small number of patients with multiple IDP $(n=2)$, we could not evaluate potential differences in upgrade rate between solitary and multiple lesions.

It has been reported that larger lesions were more likely to be upgraded to malignancy $[4,7]$. In our study, no association between lesion size and upgrade to carcinoma was found. Previous studies also suggested that older patients are at higher risk for atypia and carcinoma in papillary lesions [5]. In the present study, there was a trend for higher age in patients with an upgrade to carcinoma, although it did not reach statistical significance $(\mathrm{p}=$ 0.174).

Most previous studies investigated IDPs diagnosed with CNB, while our study additionally included IDPs verified with VAB. Regarding CNB lesions, we investigated only 14 -gauge $\mathrm{CNB}$, while in previous studies, no significant differences between the use of 11gauge and 14-gauge CNB for IDP were found [26, 27]. It could be assumed that VAB might lead to less upgrades, providing a larger tissue sample than CNB. Vales et al. [28] found that malignancy was missed less frequently with VAB compared to CNB in a study investigating 80 patients $(\mathrm{p}<0.05)$. In our study, we did not observe significant differences in upgrade rates between $\operatorname{VAB}(\mathrm{n}=14)$ and CNB $(n=46)$. Nevertheless, limitations of CNB with potential undersampling or underdiagnosis should be kept in mind.

In previous studies, the upgrade rate was substantially lower in cases with pathologic-radiologic concordance $[6,7]$. In the present study, 2 patients with IDP and subsequent upgrade after excision showed initial BI-RADS 5, indicating pathologic-radiologic discordance after initial biopsy. However, there was no significant difference between the upgrade and non-upgrade group regarding 
initial BI-RADS categorization. Thus, it should be taken into account that benign papilloma and papillary carcinoma have a considerable overlap in imaging features, and indication for surgery should be considered in any inconclusive case.

This study has some limitations additional to the retrospective study design and possible selection bias, which deserve mentioning. First, as in similar studies, our patient numbers and hence the number of upgrades to malignancy were limited, and associations with upgrade to carcinoma should therefore be regarded as preliminary. The small patient numbers could have influenced study results, so that no significant differences in upgrades between $\mathrm{CNB}$ and VAB or other characteristics could be found. Further studies with larger patient numbers are warranted to validate our findings. Second, we did not evaluate the upgrade to lesions of greater clini- cal significance other than DCIS and invasive carcinoma, such as atypical ductal or lobular hyperplasia.

In conclusion, we found an upgrade rate to carcinoma at excision for IDPs diagnosed with image-guided biopsy of $16.1 \%$. Lesions with an upgrade to malignancy after excision were significantly associated with a greater distance to the nipple. Our data suggest that observation only might not be adequate for the management of all patients with a diagnosis of IDP on biopsy. For patients with peripheral IDP, surgical excision should be considered.

\section{Disclosure Statement}

The authors have no potential conflict of interest to declare.

\section{References}

1 Lam WW, Chu WC, Tang AP, Tse G, Ma TK: Role of radiologic features in the management of papillary lesions of the breast. AJR Am J Roentgenol 2006;186: 1322-1327.

2 Renshaw AA, Derhagopian RP, Tizol-Blanco DM, Gould EW: Papillomas and atypical papillomas in breast core needle biopsy specimens: risk of carcinoma in subsequent excision. Am J Clin Pathol 2004;122: 217-221.

3 Jacobs TW, Connolly JL, Schnitt SJ: Nonmalignant lesions in breast core needle biopsies: to excise or not to excise? Am J Surg Pathol 2002;26:1095-1110.

4 Kil WH, Cho EY, Kim JH, Nam SJ, Yang JH: Is surgical excision necessary in benign papillary lesions initially diagnosed at core biopsy? Breast 2008;17:258-262.

$\checkmark 5$ Arora N, Hill C, Hoda SA, Rosenblatt R, Pigalarga R, Tousimis EA: Clinicopathologic features of papillary lesions on core needle biopsy of the breast predictive of malignancy. Am J Surg 2007;194:444-449.

6 Pareja F, Corben AD, Brennan SB, Murray MP, Bowser ZL, Jakate K, Sebastiano C, Morrow M, Morris EA, Brogi E: Breast intraductal papillomas without atypia in radiologic-pathologic concordant core-needle biopsies: rate of upgrade to carcinoma at excision. Cancer 2016;122:2819-2827.

7 Chang JM, Moon WK, Cho N, Han W, Noh DY, Park IA, Jung EJ: Risk of carcinoma after subsequent excision of benign papilloma initially diagnosed with an ultrasound (US)-guided 14-gauge core needle biopsy: a prospective observational study. Eur Radiol 2010;20: 1093-1100.

8 Liberman L, Bracero N, Vuolo MA, Dershaw DD, Morris EA, Abramson AF, Rosen PP: Percutaneous large-core biopsy of papillary breast lesions. AJR Am J Roentgenol 1999;172:331-337.

$\checkmark 9$ Mercado CL, Hamele-Bena D, Oken SM, Singer CI, Cangiarella J: Papillary lesions of the breast at percutaneous core-needle biopsy. Radiology 2006;238:801808.

-10 Sydnor MK, Wilson JD, Hijaz TA, Massey HD, Shaw de Paredes ES: Underestimation of the presence of breast carcinoma in papillary lesions initially diagnosed at core-needle biopsy. Radiology 2007;242:5862.
11 Jung SY, Kang HS, Kwon Y, Min SY, Kim EA, Ko KL Lee S, Kim SW: Risk factors for malignancy in benign papillomas of the breast on core needle biopsy. World J Surg 2010;34:261-265.

12 Kim SY, Kim EK, Lee HS, Kim MJ, Yoon JH, Koo JS, Moon HJ: Asymptomatic benign papilloma without atypia diagnosed at ultrasonography-guided 14-gauge core needle biopsy: which subgroup can be managed by observation? Ann Surg Oncol 2016;23:1860-1866.

13 Liedtke C, Thill M, Jackisch C, Thomssen C, Muller V, Janni W, Janni W; AGO Breast Committee: AGO Recommendations for the Diagnosis and Treatment of Patients with Early Breast Cancer: update 2017. Breast Care (Basel) 2017;12:172-183

14 Li X, Weaver O, Desouki MM, Dabbs D, Shyum S, Carter G, Zhao C: Microcalcification is an important factor in the management of breast intraductal papillomas diagnosed on core biopsy. Am J Clin Pathol 2012;138:789-795.

15 Khan S, Diaz A, Archer KJ, Lehman RR, Mullins T, Cardenosa G, Bear HD: Papillary lesions of the breast: to excise or observe? Breast J 2018;24:350-355.

16 Rageth CJ, O’Flynn EA, Comstock C, Kurtz C, Kubik R, Madjar H, Lepori D, Kampmann G, Mundinger A, Baege A, Decker T, Hosch S, Tausch C, Delaloye JF, Morris E, Varga Z: First International Consensus Conference on lesions of uncertain malignant potential in the breast (B3 lesions). Breast Cancer Res Treat 2016; 159:203-213.

17 Ivan D, Selinko V, Sahin AA, Sneige N, Middleton LP: Accuracy of core needle biopsy diagnosis in assessing papillary breast lesions: histologic predictors of malignancy. Mod Pathol 2004;17:165-171.

18 Ko D, Kang E, Park SY, Kim SM, Jang M, Yun B, Chae S, Jang Y, Kim HJ, Kim SW, Kim EK: The management strategy of benign solitary intraductal papilloma on breast core biopsy. Clin Breast Cancer 2017;17: $367-372$.

19 Ahmadiyeh N, Stoleru MA, Raza S, Lester SC, Golshan $\mathrm{M}$ : Management of intraductal papillomas of the breast: an analysis of 129 cases and their outcome. Ann Surg Oncol 2009;16:2264-2269.
20 Swapp RE, Glazebrook KN, Jones KN, Brandts HM, Reynolds C, Visscher DW, Hieken TJ: Management of benign intraductal solitary papilloma diagnosed on core needle biopsy. Ann Surg Oncol 2013;20:19001905

21 Chang JM, Han W, Moon WK, Cho N, Noh DY, Park IA, Jung EJ: Papillary lesions initially diagnosed at ultrasound-guided vacuum-assisted breast biopsy: rate of malignancy based on subsequent surgical excision. Ann Surg Oncol 2011;18:2506-2514.

22 Rizzo M, Linebarger J, Lowe MC, Pan L, Gabram SG, Vasquez L, Cohen MA, Mosunjac M: Management of papillary breast lesions diagnosed on core-needle biopsy: clinical pathologic and radiologic analysis of 276 cases with surgical follow-up. J Am Coll Surg 2012;214: 280-287.

23 Skandarajah AR, Field L, Yuen Larn Mou A, Buchanan M, Evans J, Hart S, Mann GB: Benign papilloma on core biopsy requires surgical excision. Ann Surg Oncol 2008;15:2272-2277.

24 Moon HJ, Jung I, Kim MJ, Kim EK: Breast papilloma without atypia and risk of breast carcinoma. Breast J 2014;20:525-533.

25 Youk JH, Kim EK, Kwak JY, Son EJ, Park BW, Kim SI: Benign papilloma without atypia diagnosed at USguided 14-gauge core-needle biopsy: clinical and US features predictive of upgrade to malignancy. Radiology 2011;258:81-88.

26 Liberman L, Tornos C, Huzjan R, Bartella L, Morris EA, Dershaw DD: Is surgical excision warranted after benign, concordant diagnosis of papilloma at percutaneous breast biopsy? AJR Am J Roentgenol 2006;186: 1328-1334.

27 Jackman RJ, Birdwell RL, Ikeda DM: Atypical ductal hyperplasia: can some lesions be defined as probably benign after stereotactic 11-gauge vacuum-assisted biopsy, eliminating the recommendation for surgical excision? Radiology 2002;224:548-554.

28 Valdes EK, Tartter PI, Genelus-Dominique E, Guilbaud DA, Rosenbaum-Smith S, Estabrook A: Significance of papillary lesions at percutaneous breast biopsy. Ann Surg Oncol 2006;13:480-482. 